\section{One- and two-step hydrogen peroxide contact lens
disinfection
solutions against
Acanthamoeba:
How effective are
they? contact lens
disinfection
solutions against
Acanthamoeba:
How effective are
they? contact lens
disinfection
solutions against
Acanthamoeba:
How effective are
they? contact lens
disinfection
solutions against
Acanthamoeba:
How effective are
they? contact lens
disinfection
solutions against
Acanthamoeba:
How effective are
they? contact lens
disinfection
solutions against
Acanthamoeba:
How effective are
they?}

Abstract

Purpose Effective contact lens disinfection solutions are important to keep the storage case free of acanthamoebae and thus prevent an infection of the eye. The aim of our study was to evaluate the effectivity of two new onestep hydrogen peroxide disinfecting solutions against Acanthamoeba spp. and compare it to the effectivity of other commercially available systems.

Methods Nine one-step 3\% hydrogen peroxide systems including the new systems Silver Sept (platinum and silver disk for intensifying disinfection) and Blue Vision (newly composed catalytic tablet) and 2 two-step systems (0.6 and $3.0 \% \mathrm{H}_{2} \mathrm{O}_{2}$ ) were tested for their effectivity against cysts of two Acanthamoeba keratitis isolates at different concentrations.

Results After a soaking time of $8 \mathrm{~h}$ (overnight soaking of contact lenses) the 2 two-step systems completely destroyed the cysts of both Acanthamoeba strains, even at the highest concentration of cysts tested. The nine tested one-step systems showed weaker effects. The new Blue Vision system was able to eradicate the cysts of one strain at the low concentration of cysts.

Conclusions One-step hydrogen peroxide systems do not have sufficient effects on Acanthamoeba cysts and therefore may not protect the contact lens user from a possible infection of the eye. Further development of tablets like the ones used in the Blue Vision system may result in better cysticidal effects for one-step systems.

Eye (2005) 19, 1301-1305. doi:10.1038/sj.eye.6701752; published online 12 November 2004
K Hiti' , J Walochnik², C Faschinger ${ }^{1}$,

E-M Haller-Schober ${ }^{1}$ and $\mathrm{H}$ Aspöck ${ }^{2}$

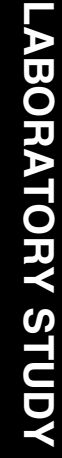

Keywords: Acanthamoeba; hydrogen peroxide; contact lenses; disinfection

\section{Introduction}

Contact lens wearing is the main risk factor for keratitis caused by Acanthamoeba. ${ }^{1}$ Several studies have shown that the contact lens storage case is a potential source and reservoir of these parasites. Acanthamoebae have been isolated from the lens storage cases of many patients in whom Acanthamoeba keratitis has been diagnosed and also from contact lens cases of asymptomatic lens wearers. ${ }^{1,2-6}$ Acanthamoeba trophozoites and cysts attach to the surface of the contact lens and can therefore be transmitted from the contaminated storage case onto the eye in high concentrations. ${ }^{7}$ The adherence depends on the lens type and material and is significantly higher with high water content soft contact lenses than with rigid gas permeable lenses, which probably explains the greater risk for soft contact lens wearers. ${ }^{7}$ Corneal microtraumata in connection with the use of contact lenses represent an open door for Acanthamoeba invasion and the devastating infection of the eye. 8

In the early stage, the infection is often misdiagnosed as a Herpes simplex or fungal keratitis. ${ }^{10,11}$ The treatment of Acanthamoeba keratitis is most successful in those cases in which the diagnosis is made very early. ${ }^{11,12-14}$ However, the most important aspect in the management of Acanthamoeba keratitis is prevention. Therefore the use of contact lens storage solutions that reliably kill Acanthamoeba trophozoites and cysts is of great importance.
${ }^{1}$ Department of Ophthalmology, University of Graz, Austria

${ }^{2}$ Department of Medical Parasitology, Clinical Institute of Hygiene and Medical Microbiology, Medical University of Vienna,

Austria

Correspondence: H Aspöck, Department of Medical Parasitology,

Clinical Institute of Hygiene and Medical Microbiology, Medical University of Vienna,

Kinderspitalgasse 15 1095 Vienna, Austria, Tel: + 4301427779430 Fax: + 43142779794 . E-mail: Horst.Aspoeck@ meduniwien.ac.at

Received: 12 July 2004 Accepted: 7 September 2004

Published online:

12 November 2004

The authors have no commercial or financial interests in any products mentioned in this study. 
Table 1 Contact lens solutions tested

\begin{tabular}{|c|c|c|c|c|}
\hline Trade name & Manufacturer & System & $\begin{array}{l}\text { Hydrogen } \\
\text { peroxide }\end{array}$ & Lens-Type \\
\hline Oxysept $^{\mathbb{R}} 1$ & Pharm Allergan GmbH D-76260 Ettlingen & Two-step catalase solution $520 \mathrm{U} / \mathrm{ml}$ & $3 \% \mathrm{H}_{2} \mathrm{O}_{2}$ & Soft \\
\hline Titmus $\mathrm{H}_{2} \mathrm{O}_{2}$ & CIBA Vision Corp. Duluth GA 30097, USA & Two-step catalase solution $170 \mathrm{U} / \mathrm{ml}$ & $0.6 \% \mathrm{H}_{2} \mathrm{O}_{2}$ & $\begin{array}{l}\text { Soft and rigid } \\
\text { gas permeabel }\end{array}$ \\
\hline Oxysept ${ }^{\circledR}$ & Pharm Allergan GmbH D-76260 & & & \\
\hline Comfort & Ettlingen & One-step catalase $0.1 \mathrm{mg} /$ tablet & $3 \% \mathrm{H}_{2} \mathrm{O}_{2}$ & Soft \\
\hline ONS MERK 1 & Oté Pharma Sol BV-NL 5406-XP Uden & One-step catalase tablet no details & $3 \% \mathrm{H}_{2} \mathrm{O}_{2}$ & Soft \\
\hline BLUE VISION & CIBA Vision Corp. Duluth GA 30097, USA & One-step catalase $0.3 \mathrm{mg} /$ tablet & $3 \% \mathrm{H}_{2} \mathrm{O}_{2}$ & Soft \\
\hline Silver Sept & $\begin{array}{l}\text { MDLE Gmbh Germ.-87700 } \\
\text { Memmingen }\end{array}$ & One-step platin disk and silver disk & $3 \% \mathrm{H}_{2} \mathrm{O}_{2}$ & Soft \\
\hline $\begin{array}{l}\text { Concerto }^{\mathbb{R}} \\
\text { platinum }\end{array}$ & Lab. Contapharm France-77390 Creteil & One-step platin disk & $3 \% \mathrm{H}_{2} \mathrm{O}_{2}$ & Soft \\
\hline easy ${ }^{\circledR}$ SEPT & Bausch\&Lomb IOM S.p.A.-2005 Ital., Milano & One-step platin disk & $3 \% \mathrm{H}_{2} \mathrm{O}_{2}$ & Soft \\
\hline CONTACT & Wöhlk C.L. Gm-bh, Germ.-24232 & One-step platin disk & $3 \% \mathrm{H}_{2} \mathrm{O}_{2}$ & Soft \\
\hline \multirow[t]{2}{*}{$\begin{array}{l}\text { CARE SOFT } \\
\text { contopharma }\end{array}$} & Schönkirchen & & & \\
\hline & Contopharma AG CH -3800, Interlaken & One-step catalase solution $111 \mathrm{U} / \mathrm{ml}$ & $3 \% \mathrm{H}_{2} \mathrm{O}_{2}$ & Soft \\
\hline AOSEPT & CIBA Vision Corp. Duluth GA 30097, USA & One-step platin disk & $3 \% \mathrm{H}_{2} \mathrm{O}_{2}$ & Soft \\
\hline
\end{tabular}

The two most popular types of contact lens storage solutions are multipurpose disinfection systems on one hand and one-step hydrogen peroxide systems on the other. In this study, the effect of nine one-step hydrogen peroxide contact lens storage and disinfection solutions and 2 two-step systems on different Acanthamoeba strains was tested.

\section{Materials and methods}

\section{Contact lens solutions}

All contact lens disinfection solutions tested (Table 1) were purchased from local retail stores. The solutions were taken from the original wrappings and used before their stated expiry date. In case of the two-step systems Titmus $\mathrm{H}_{2} \mathrm{O}_{2}\left[\begin{array}{lll}0.6 \% & \mathrm{H}_{2} \mathrm{O}_{2}\end{array}\right]$ and Oxysept ${ }^{\circledR} 1\left[\begin{array}{lll}3 \% & \mathrm{H}_{2} \mathrm{O}_{2}\end{array}\right]$ neutralisation of the hydrogen peroxide is achieved by soaking the contact lenses in a second catalytic solution for $10 \mathrm{~min}$ before wearing.

In five of the tested one-step systems (Concerto ${ }^{\circledR}$ platinum, AOSEPT, Contact care soft, easy ${ }^{\circledR}$ SEPT and Silver Sept) neutralisation of the $3 \%$ hydrogen peroxide is achieved within $6 \mathrm{~h}$ by a catalytic platinum disk which is located in the contact lens storage case. In the Silver Sept system additionally to the platinum disk on the bottom of the storage case, a small silver disk is attached to the contact lens storage basket. This silver disk releases silver ions during the disinfecting process, intensifying disinfection and suppressing microbial multiplication.

In three of the four other one-step systems tested (Blue VISION, ONS MERK 1 and Oxysept ${ }^{\circledR}$ Comfort) a catalytic tablet is put into the storage case together with the $3 \%$ hydrogen peroxide solution requiring a minimum lens soaking time for disinfection and neutralisation of $6 \mathrm{~h}$.

The one-step system contopharma ${ }^{\circledR}$ works with two solutions. After pouring $4 \mathrm{ml}$ of a catalytic solution into a marked contact lens storage case, $4 \mathrm{ml}$ of a $3 \%$ hydrogen peroxide solution are added and the contact lenses are soaked whereby disinfection and neutralisation should be achieved within 20 min of soaking time.

\section{Acanthamoeba}

Two different strains of Acanthamoeba spp. belonging to morphological group II were used in this study. Both strains, the 11DS strain of Acanthamoeba hatchetti and the 1BU strain of Acanthamoeba castellanii, had been isolated from patients suffering from a severe Acanthamoeba keratitis. ${ }^{15,16}$ Isolation had been achieved by inoculating corneal epithelium onto non-nutrient agar plates covered with a 48-h-old culture of Escherichia coli.

The isolates were cloned by transferring a single cyst onto a fresh plate with a micromanipulator. Axenisation was achieved by harvesting cysts from parallel cultures and incubating them in $3 \% \mathrm{HCl}$ overnight in order to eliminate coexisting bacteria. The cysts were then transferred to sterile filtrated proteose peptone-yeast extract-glucose (PYG), ${ }^{17}$ that was used as axenic medium further on. Synchronised encystment of the amoebae was achieved by long-term storage without the addition of fresh medium. The process of encystment including morphological changes of the cyst wall was observed daily by phase-contrast microscopy. After 14 days the 
cysts of both strains were in their mature stage. The cysts were harvested by centrifugation $(500 \mathrm{~g} / 7 \mathrm{~min})$, resuspended in sterile $0.9 \% \mathrm{NaCl}$ and counted in a Bürker-Türk haemocytometer. Of each strain two suspensions were prepared, one with $10^{4}$ and one with $10^{5}$ cysts $/ \mathrm{ml}$, respectively.

\section{Performance of the tests}

Tests were performed in $15 \mathrm{ml}$ centrifugation tubes. A measure of $100 \mu \mathrm{l}$ of the respective cyst suspension $\left(10^{3}\right.$ and $10^{4}$ cells) and $8 \mathrm{ml}$ of the respective contact lens solution were added per tube. All solutions were used according to the manufacturers' instructions.

The two-step solutions were directly added to the tubes. For the one-step systems working with a catalytic disk, the platin ring was installed prior to the addition of the $3 \%$ hydrogen peroxide solution. For the systems working with a catalytic tablet, the tablet was added immediately after addition of the 3\% hydrogen peroxide solution. Silver Sept tests were performed in the original contact lens case because of the silver disk attached to the contact lens basket.

After a soaking time of $8 \mathrm{~h}$ the pellets (after $500 \mathrm{~g} /$ 7 min centrifugation) of the respective tubes were inoculated onto non-nutrient agar plates covered with a layer of E. coli. The plate cultures were sealed and incubated at $30^{\circ} \mathrm{C}$ for 14 days. Amoebic growth was observed daily by phase-contrast microscopy. All experiments were carried out in triplicate. The control groups were performed with sterile $0.9 \% \mathrm{NaCl}$.

\section{Results}

The effect of the 11 hydrogen peroxide contact lens disinfecting solutions on the two different Acanthamoeba strains is shown in Table 2. Generally, the two-step systems Titmus $\mathrm{H}_{2} \mathrm{O}_{2}$ and Oxysept ${ }^{\circledR} 1$ showed the best amoebicidal effects. After $8 \mathrm{~h}$ of soaking, the cysts of both strains, A. hatchetti and A. castellanii, were completely destroyed independently from cyst concentration. The one-step systems Blue Vision (tablet) and AOSEPT (platin disk) were effective against $10^{3}$ cysts of $A$. hatchetti, while cysts at higher concentration $\left(10^{4}\right)$ and those of $A$. castellanii were still viable after exposure to these solutions for $8 \mathrm{~h}$. All other solutions working with a platin disk (Concerto ${ }^{\circledR}$ platinum, easy Sept and Contact care soft) or with a catalytic tablet for neutralisation of the $3 \%$ hydrogen peroxide (Oxysept ${ }^{\mathbb{R}}$ Comfort and ONS MERK 1), were not able to eradicate the Acanthamoeba cysts at any concentration within $8 \mathrm{~h}$ of soaking time. Cysts of both tested strains and concentrations were still viable. Also Silver Sept, working with a platin and a silver disk and contopharma ${ }^{\circledR}$ (the one-step system with
Table 2 Viability of Acanthamoeba cysts after $8 \mathrm{~h}$ of exposure time

\begin{tabular}{|c|c|c|c|c|}
\hline & \multicolumn{2}{|c|}{ A. hatchetti (11 DS) } & \multicolumn{2}{|c|}{ A. castellanii (1 BU) } \\
\hline & $10^{3}$ & $10^{4}$ & $10^{3}$ & $10^{4}$ \\
\hline Oxysept $^{(\mathbb{R}} 1$ & - & - & - & - \\
\hline Titmus $\mathrm{H}_{2} \mathrm{O}_{2}$ & - & - & - & - \\
\hline BLUE VISION & - & + & + & + \\
\hline AOSEPT & - & + & + & + \\
\hline Oxysept ${ }^{\mathbb{R}}$ Comfort & + & + & + & + \\
\hline Silver Sept & + & + & + & + \\
\hline Concerto ${ }^{\mathbb{R}}$ platinum & + & + & + & + \\
\hline Easy $^{\circledR}$ Sept & + & + & + & + \\
\hline Contact care soft & + & + & + & + \\
\hline ONS MERK 1 & + & + & + & + \\
\hline Contopharma & + & + & + & + \\
\hline Control $0.9 \% \mathrm{NaCl}$ & + & + & + & + \\
\hline
\end{tabular}

a hydrogen peroxide solution and a neutralising solution) gave positive cultures after $8 \mathrm{~h}$ of soaking time with either Acanthamoeba strain and at either concentration.

Both Acanthamoeba strains belong to morphological group II, however, A. castellanii was found to be slightly more resistant than $A$. hatchetti.

\section{Discussion}

Our study has shown that not all of the different hydrogen peroxide contact lens storage and disinfecting systems tested are effective against Acanthamoeba cysts. After an exposure time of $8 \mathrm{~h}$, the two tested two-step systems, Titmus $\mathrm{H}_{2} \mathrm{O}_{2}$ and Oxysept ${ }^{\circledR} 1$, were able to completely eradicate the Acanthamoeba cysts at either concentration tested. The nine tested one-step systems working with $3 \%$ hydrogen peroxide were less effective.

Three per cent hydrogen peroxide is a very capable disinfectant against a wide variety of microorganisms and ocular pathogens. ${ }^{18}$ An incubation of $15 \mathrm{~min}$ is sufficient to kill most bacteria and to inactivate HIV, for Acanthamoeba an incubation of $1-3 \mathrm{~h}$ with $3 \%$ hydrogen peroxide is necessary. ${ }^{18-20}$

However, hydrogen peroxide is toxic to the ocular epithelium. ${ }^{21}$ In one-step systems neutralisation of the hydrogen peroxide is achieved by a catalytic platinum disk or a tablet containing catalase which is located into the contact lens storage case. These systems are very comfortable for the contact lens wearer. According to the manufacturers' instructions neutralisation and disinfection are achieved by one-step within a period of $6 \mathrm{~h}$ and the contact lens can be brought directly onto the eye.

Among the one-step systems working with a catalytic tablet Blue Vision (0.3 mg catalase/tablet) completely 
destroyed $A$. hatchetti at a concentration of $10^{3}$ cells $/ \mathrm{ml}$, whereas Oxysept ${ }^{\circledR}$ Comfort and Ons Merk 1 did not. In Oxysept ${ }^{\circledR}$ Comfort (0.1 mg catalase/tablet) and Ons Merk 1 the neutralisation of the hydrogen peroxide to oxygen and water by the catalase tablet starts immediately. In the Blue Vision system it takes 55-65 min of tablets' soaking time to decompose the blue capsule of the tablet and release catalase from the nucleus. After that time the neutralisation of the hydrogen peroxide starts promptly. These findings may explain the better results of the Blue Vision system compared to the two other one-step systems based on a catalase tablet.

Too early neutralisation of the $3 \%$ hydrogen peroxide could be avoided by the development of more durable tablet-capsules and therefore make one-step systems safer for contact lens users.

Among the systems working with a platin disk AOSEPT ( $3 \%$ hydrogen peroxide with $0.85 \%$ sodium chloride), completely destroyed $A$. hatchetti at a concentration of $10^{3}$ cells $/ \mathrm{ml}$, whereas the other platin disk systems did not show enough effectivity to completely eradicate the Acanthamoeba cysts at either concentration. The reasons for the better activity of the AOSEPT system in comparison to the other platin disk systems are unclear. Silvany et $a l^{19}$ demonstrated the viability of two Acanthamoeba species after $8 \mathrm{~h}$ exposure to AOSEPT and Hughes and Kilvington ${ }^{20}$ described a $1.28 \log$ reduction of $A$. polyphaga after $4 \mathrm{~h}$ contact time to AOSEPT. Differences in stabilising ingredients, $\mathrm{pH}$, and neutralisation time of the hydrogen peroxide may result in the varying amoebicidal effect for different products containing the same concentration of hydrogen peroxide and a catalytic platinum disk for neutralisation.

Interesting results for platin disk systems have been shown by Hughes et al. ${ }^{22}$ A combination of horseradish peroxidase, $\mathrm{KI}$, and $\mathrm{H}_{2} \mathrm{O}_{2}$ showed an enhanced cysticidal activity compared to hydrogen peroxide alone, and was also effective when tested with a platinum disk system.

The normal period of time for contact lenses to be disinfected would be overnight while the wearer is not using them. Thus a soaking time of $8 \mathrm{~h}$ was of main interest in our study. Our results showing the good cysticidal activity of the two-step system Oxysept 1 correspond to those of other studies and can be explained by the long exposure time to $3 \%$ hydrogen peroxide which is not deactivated by a catalytic system (tablet or disk). ${ }^{20,23}$ Although the Titmus $\mathrm{H}_{2} \mathrm{O}_{2}$ system for disinfection of soft and rigid contact lenses works with hydrogen peroxide at a concentration of only $0.6 \%$, it is more effective than the one-step systems, that contain 3\% $\mathrm{H}_{2} \mathrm{O}_{2}$, but in that the neutralisation process starts immediately. This shows clearly, that also with $0.6 \%$ $\mathrm{H}_{2} \mathrm{O}_{2}$ a complete destruction of Acanthamoeba cysts can be achieved, if this concentration is held up during $8 \mathrm{~h}$ and not deactivated by a catalytic system. However, the $\mathrm{H}_{2} \mathrm{O}_{2}$ concentration must not be lower than $0.6 \%$. Zanetti et al tested the hydrogen peroxide of two contact lens solutions against a corneal isolate of $A$. castellanii. A $1: 2$ dilution of this solution (1.5\%) killed the cysts after a $9 \mathrm{~h}$ exposure, but after exposure to a $1: 10$ dilution (0.3\%), $25 \%$ of the cysts were still viable. ${ }^{24}$

In our study, $A$. hatchett $i$ showed a higher degree of sensitivity against the tested contact lens solutions, than A. castellanii. The susceptibility of Acanthamoeba cysts to disinfection is dependent on the cyst age, ${ }^{25,26}$ but also on the cyst structure of the particular strain. Several studies have shown that the sensitivity of Acanthamoeba cysts against contact lens disinfectants varies between the different strains and morphological groups. . $^{123,27-28}$ Acanthamoeba cysts are slightly smaller than the trophozoites with a size of $12-28 \mu \mathrm{m}$ in diameter. They are double-walled consisting of an interior endocyst, which can be stellate, polygonal or even round, and an exterior wrinkled ectocyst. The cyst walls are laminated and united at several sites. Where the endocyst and the ectocyst meet, characteristic pores are found. ${ }^{12,29}$ The thickness of the cyst wall and the number of pores may influence the biocide susceptibility of the particular strain.

A contact lens disinfecting solution that does not kill both Acanthamoeba trophozoites as well as cysts is not suitable for protecting the contact lens user from a posssible infection with these pathogens. The results of our study demonstrate that commercially available onestep hydrogen peroxide disinfecting systems are not effective enough against Acanthamoeba cysts because of rapid hydrogen peroxide neutralisation.

Further development of catalytic tablets like tested in the Blue Vision system should make one-step systems safer for the contact lens wearer. Adequate exposure times to $3 \% \mathrm{H}_{2} \mathrm{O}_{2}$ may be achieved by the development of more durable tablet capsules, protecting the catalytic nucleus for $2-3 \mathrm{~h}$ and therefore avoiding too early neutralisation of the hydrogen peroxide.

We recommend the tested two-step sytems (Titmus $\mathrm{H}_{2} \mathrm{O}_{2}$, Oxysept ${ }^{\circledR}$ 1) for the storage and disinfection of contact lenses.

\section{References}

1 Moore MB, McCulley JP, Newton C, Cobo LM, Foulks GN, $\mathrm{O}^{\prime}$ Day DM et al. Acanthamoeba keratitis. A growing problem in soft and hard contact lens wearers. Ophthalmology 1987; 94: 1654-1661.

2 Dart J. Contamination of storage cases. Br J Opthalmol 1990; 74: 129-132.

3 Larkin DFP, Kilvington S, Easty DL. Contamination of contact lens storage cases by Acanthamoeba and bacteria. $\mathrm{Br} \mathrm{J}$ Ophthalmol 1990; 74: 133-135. 
4 Devonshire P, Munroe FA, Abernethy C, Clark BJ. Microbial contamination of contact lens cases in the west of Scotland. Br J Ophthalmol 1993; 77: 41-45.

5 Gray TB, Cursons RTM, Sherwan JF, Rose PR. Acanthamoeba, bacterial, and fungal contamination of contact lens storage cases. Br J Ophthalmol 1995; 79: 601-605.

6 Radford CF, Minassian DC, Dart JGK. Acanthamoeba keratitis in England and Wales: incidence, outcome, and risk factors. Br J Ophthalmol 2002; 86: 536-542.

7 Kilvington S, Larkin DFP. Acanthamoeba adherence to contact lenses and removal by cleaning agents. Eye 1990; 4 : 589-590.

8 Van Klinik F, Alizadeh H, He YG, Mellon JA, Silvany RE, McCulley JP et al. The role of contact lens trauma and Langerhans cells in a Chinese hamster model of Acanthamoeba keratitis. Invest Ophthalmol Vis Sci 1993; 34: 1937-1944.

9 Niederkorn JY, Alizadeh H, Lehrer H, McCully JP. The pathogenesis of Acanthamoeba keratitis. Microbes Infect 1999; 1: 437-443.

10 Bacon AS, Frazer DG, Dart JGK, Matheson M, Ficker LA, Wright P. A review of 72 consecutive cases of Acanthamoeba keratitis. Eye 1993; 7: 719-725.

11 Lindquist TD, Doughman DJ. Clinical signs and medical therapy of early Acanthamoeba keratitis. Arch Ophthalmol 1988; 106: 73-77.

12 Illingworth CD, Cook SD. Acanthamoeba keratitis. Surv Ophthalmol 1998; 42: 493-508.

13 Lindquist TD. Treatment of Acanthamoeba keratitis. Cornea 1998; 17: 11-16.

14 Larkin DFP, Kilvington S, Dart JKG. Treatment of Acanthamoeba keratitis with polyhexamethylene biguanide. Ophthalmology 1992; 99: 185-191.

15 Walochnik J, Obwaller A, Aspöck H. Correlations between morphological, molecular biological, and physiological characteristics in clinical and nonclinical isolates of Acanthamoeba spp. Appl Environ Microbiol 2000; 66: 4408-4413.

16 Walochnik J, Haller-Schober EM, Kölli H, Picher O, Obwaller A, Aspöck H. Discrimination between clinically relevant and nonrelevant Acanthamoeba strains isolated from contact lens wearing keratitis patients in Austria. J Clin Microbiol 2000; 38: 3932-3936.

17 Page FC. Nackte Rhizopoda. Germany: Protozoenfauna, Band 2 G. Fischer: Stuttgart, 1991; 3-145.
18 Smith CA, Pepose JS. Disinfection of tonometers and contact lenses in the office setting: are current techniques adequate? Am J Ophthalms 1999; 127: 77-83.

19 Silvany RE, Dougherty JM, McCulley JP, Wood TS, Bowman RW, Moore MB. The effect of currently available contact lens disinfection systems on Acanthamoeba castellanii and Acanthamoeba polyphaga. Ophthalmology 1990; 97: 286-290.

20 Hughes R, Kilvington S. Comparison of hydrogen peroxide contact lens disinfection systems and solutions against Acanthamoeba polyphaga. Antimicrob Agents Chemother 2001; 45: 2038-2043.

21 Tripathi BJ, Tripathi RC, Millard CB, Borisuth NS. Cytotoxicity of hydrogen peroxide to human corneal epithelium in vitro and its clinical implictions. Lens Eye Toxic Res 1990; 7: 385-401.

22 Hughes R, Andrew PW, Kilvington S. Enhanced killing of Acanthamoeba cysts with a plant peroxidase-hydrogen peroxide-halide antimicrobial system. Appl Environ Microbiol 2002; 69: 2563-2567.

23 Niszl IA, Markus MB. Anti-Acanthamoeba activity of contact lens solutions. Br J Ophthalmol 1998; 82: 1033-1038.

24 Zanetti S, Fiori PL, Pinna A, Usai S, Carta F, Fadda G. Susceptibility of Acanthamoeba castellanii to contact lens disinfecting solutions. Antimicrob Agents Chemother 1995; 39: 1596-1598.

25 Kilvington S, Anger C. A comparison of cyst age and assay method of the efficacy of contact lens disinfectants against Acanthamoeba. Br J Ophthalmol 2001; 85: 336-340.

26 Hughes R, Haselgrave W, Kilvington S. Acanthamoeba polyphaga strain age and method of cyst production influence the observed efficacy of therapeutic agents and contact lens disinfectants. Antimicrob Agents Chemother 2003; 47: 3080-3084.

27 Silvany RE, Dougherty JM, McCulley JP. Effect of contact lens preservatives on Acanthamoeba. Ophthalmology 1991; 98: 854-857.

28 Hiti K, Walochnik J, Haller-Schober EM, Faschinger C, Aspöck H. Viability of Acanthamoeba after exposure to a multipurpose disinfectant contact lens solution and two hydrogen peroxide sytems. Br J Ophthalmol 2002; 86: 144-146.

29 Pussard M, Pons R. Morphologie de la paroi kystique et taxonomie du genre Acanthamoeba (Protozoa Amoebida) Protistologica 1977; 8: 557-598. 